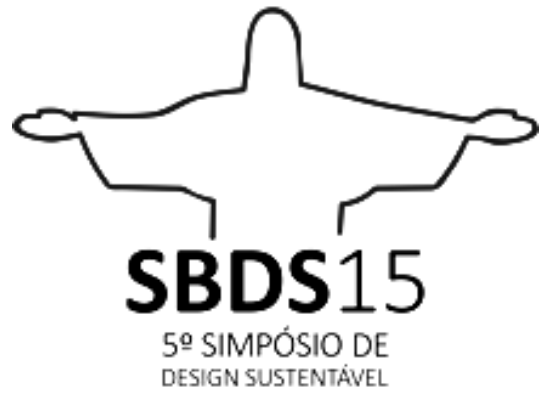

Rio de Janeiro, 11 de novembro a 13 de novembro de 2015

\title{
DESIGN E ARTESANATO: relações de poder ${ }^{1}$
}

\author{
Marcela Fonseca Lima \\ Pontifícia Universidade Católica - Rio de Janeiro \\ marcela.lima@ aluno.puc-rio.br
}

\begin{abstract}
Resumo: O artesanato possui importante papel na economia e na cultura do Brasil, empregando um grande número de pessoas e gerando renda para várias famílias. No entanto, apesar de sua importância, essa atividade ainda é vista frequentemente com preconceito no país. Existe um esforço dos designers, a partir da década de 1980, na busca da revitalização e valorização do artesanato, tais profissionais procuram preservar as técnicas produtivas e incorporar novos elementos formais e/ou técnicos aos objetos artesanais. Esse artigo problematiza as relações estabelecidas entre os dois saberes e discute as relações de poder envolvidas nessa aproximação, avaliando os campos de projeto, estética e mercado.
\end{abstract}

Palavras-chave: Design, artesanato, projeto, estética e mercado.

Abstract: Craft activity has an important role in the economy and culture of Brazil, employing a large number of people and generating income for family. However, despite its importance, this activity is still seen with prejudice in the country. Since 1980 there is an effort by designers to revitalize and enhance craft. Such professionals seek to preserve the productive techniques and incorporate new formal elements and/or technicians to handmade objects. This article debates the relations between the two knowledge and discusses the power relations involved in this approach, evaluating the fields of design, aesthetic and market.

Keywords: Design, craft, aesthetic and market.

\section{INTRODUÇÃO}

\footnotetext{
${ }^{1}$ Trabalho desenvolvido durante a disciplina Subjetividade no design - realizada no programa de pós-graduação em Design da PUC Rio - com orientação da professora Denise Portinari.
} 
Forty (2007), em seu livro Objetos de desejo, descreve a história do design como a história das sociedades, mostrando que qualquer mudança que ocorra no design afeta os processos das economias modernas e vice-versa. Percebemos atualmente uma preocupação crescente com o meio ambiente e as relações sociais em nossa sociedade. Usando a lógica de Forty, podemos considerar que essas novas preocupações afetam o papel do designer, e nesse sentindo florescem correntes que buscam soluções mais sustentáveis.

Os bens manufaturados encarnam inumeráveis mitos sobre o mundo, mitos que acabam parecendo tão reais quanto os produtos em que estão encarnados. Cabe ao designer - que tem capacidade de moldar os mitos numa forma sólida, tangível e duradoura - conjugar esses mitos aos meios de produção de tal modo que pareçam ser a própria realidade (FORTY, 2007). Ou mais radicalmente, de tal modo que produzam essa mesma realidade. Nesse papel, o designer auxiliou a moldar a forma como entendemos e vivemos o lar, o trabalho, a tecnologia, a higiene e até mesmo nossa identidade e individualidade. Agora com as novas demandas o designer pode ser um facilitador para atingirmos uma sociedade mais sustentável.

Del Gaudio (2014) comenta que o âmbito de ação do design expandiu-se e cada vez mais é associado à resolução de questões transversais, que pertencem ao âmbito social. Para dar suporte a esta atuação, várias abordagens e ferramentas têm sido desenvolvidas e divulgadas por consultorias e centros de ensinos em design. Essas ferramentas têm como premissa a participação do usuário no processo projetual, o que permite um desenvolvimento mais adequado ao contexto, enquanto baseado nas necessidades reais dos interessados, nos recursos disponíveis e no conhecimento local. A participação implica uma partilha do poder de tomada de decisão que é normalmente exercido pelo designer e por quem encomenda o projeto, e isso favorece a possibilidade de uma participação democrática. Essa visão permite uma interação de mutuaapropriação nas intervenções entre design e outros campos, fugindo de processos unilaterais em que o designer é protagonista e avaliador da intervenção.

Um dos caminhos que os designers estão seguindo nessa busca são as interferências no artesanato. $\mathrm{O}$ artesanato apresenta importante papel na economia e na cultura do Brasil. Segundo Borges (2011), órgãos do governo divulgam desde 2001 a existência de 8,5 milhões de artesãos no país, alertando que esses dados não são totalmente precisos já que existe grande parcela de trabalhadores informais. Trata-se de uma atividade econômica relevante para o país, podendo estar entre os cinco maiores contribuintes para o Produto Interno Bruto (PIB) brasileiro:

Um artesão que vive nas grandes cidades movimenta cerca de três salários mínimos por mês; e o das pequenas cidades, meio salário mínimo. Esses números são reais, temos feito levantamento nesse sentido. Então, se fizermos uma média de um salário mínimo por mês por artesão e multiplicarmos por 8,5 milhões, teremos uma cifra de R\$ 55 bilhões anuais. (BORGES, 2011)

Apesar de sua importância, o artesanato ainda é visto frequentemente com preconceito no país. Borges (2011) analisa como a expressão artesanal é conceituada em dicionários brasileiros e europeus. No Brasil, a expressão ganha uma conotação depreciativa relacionada à ausência de sofisticação e feitura rudimentar ou grosseira, enquanto em um dicionário inglês, a palavra craft significa fazer de maneira habilidosa. A autora ressalta que o dicionário apresenta indícios da visão de uma sociedade em determinada época sobre um determinado tema. Nesse caso, é possível observar essa depreciação do artesanato em nossa sociedade que tende a desvalorizar o que é feito pelas classes C, D e E. Reverter esse quadro, tornar a atividade mais rentável para quem a pratica e resgatar seu importante papel cultural é uma possível contribuição do design.

O encontro do design e artesanato no Brasil começa nos anos $1960 \mathrm{com}$ as atuações de Lina Bo Bardi - que divulgou a produção artesanal em museus e galerias e defendeu seu estudo e preservação - e Aloísio Magalhães, que pesquisou e registrou o artesanato brasileiro através do 
CNRC $^{2}$ - sendo considerados vanguardistas na valorização dos artefatos e da cultura popular brasileira. Houve um distanciamento das duas áreas nas décadas de 1970 e 1980, quando foi marcante o antagonismo entre as áreas e o pensamento dominante dos designers era de resistir em conectar os dois campos. A partir dos anos 1990, a reaproximação é alavancada pelo discurso de desenvolvimento sustentável ${ }^{3}$ e o aparecimento de diversas instituições de fomento.

O presente trabalho busca lançar luzes a esse encontro e fazer uma breve análise da relação entre os dois saberes através de uma revisão bibliográfica.

\section{DESENVOLVIMENTO}

Vários projetos foram desenvolvidos relacionando as áreas de design e artesanato e novas metodologias foram criadas visando melhor atender às necessidades de designers e artesãos. Vários discursos - pregando, por exemplo, inovação social, sustentabilidade e preservação das tradições socioculturais - foram usados pelos designers. No entanto, essa relação é pouco problematizada. Esse trabalho procura questionar essa relação utilizando autores como Foucault, Argan e Ricardo Lima.

\subsection{0 artesanato}

Existe uma vasta discussão sobre o que é "artesanato" e vários autores e instituições propõem definições e classificações. Não vou me aprofundar na discussão, levantando os vários tipos e as distinções entre, por exemplo, folclore e arte popular, o que seria uma forma de aprisionamento como destaca Borges (2011). Além disso, esse não é do escopo do trabalho, no entanto, acredito que algumas delimitações e questionamentos se fazem necessários.

O Programa do Artesanato Brasileiro $(\mathrm{PAB})^{4}$ entende que artesanato:

[...] é o produto resultante da transformação da matéria prima, com predominância manual, por um indivíduo que detenha o domínio integral de uma ou mais técnicas previamente conceituada, aliando criatividade, habilidade e valor cultural, com ou sem expectativas econômicas, podendo no processo ocorrer o auxílio limitado de máquinas, ferramentas, artefatos e utensílios. (MDIC apud Abbonizio, 2009)

Já a definição da UNESCO é:

Produtos artesanais são aqueles confeccionados por artesãos, seja totalmente a mão, com uso de ferramentas ou até mesmo por meios mecânicos, desde que a contribuição direta

\footnotetext{
2 O Centro Nacional de Referência Cultural/CNRC, segundo Anastassakis (2007), pretendia criar uma rede de referências da cultura brasileira buscando evitar a descaracterização e extinção das culturas locais e promover, no país, um desenvolvimento verdadeiramente autônomo.

${ }^{3} \mathrm{O}$ termo desenvolvimento sustentável entra no debate internacional pela primeira vez no documento da Comissão Mundial para o Ambiente e o Desenvolvimento chamado "Nosso futuro comum" (Our Common Future) e tinha coordenação de Gro Harlem Brundland. O relatório propôs a aliança entre o desenvolvimento e a preocupação com meio ambiente, aliando desenvolvimento e controle de recursos naturais. O termo se torna palavra-chave dentro dessa temática a partir da conferência sobre Ambiente e Desenvolvimento organizada pelas Organização da Nações Unidas (ONU) em 1992 no Rio de Janeiro, que ficou conhecida como ECO-92 (MANZINI, 2008).

${ }^{4}$ Segundo Serafim (2015) o PAB é criado em 1995 pelo Ministério de Desenvolvimento, Indústria e Comércio Exterior que firmou estratégias de interesse político para o artesanato nacional. Suas ações visam promover maior competitividade ao produto artesanal e aumentar a capacidade empreendedora do trabalhador para melhor inserir o artesanato brasileiro nos mercados nacionais e internacionais.
} 
manual do artesão permaneça como componente mais substancial do produto acabado. Essas peças são produzidas sem restrição em termos de quantidade e com o uso de matériasprimas de recursos sustentáveis. A natureza especial dos produtos artesanais deriva de suas características distintas, que podem ser utilitárias, estéticas, artísticas, criativas, de caráter cultural e simbólicas e significativas do ponto de vista social. (UNESCO apud Borges, 2011)

É importante observar que essas definições não enfatizam a relação que o artesanato tem com a realidade em que está inserido, fator primordial ao artesão, já que muitas vezes seu trabalho vem a partir dela. Nesse contexto, Hage (2009) lembra que não devemos dirigir nossas atenções apenas para o produto final, as relações e os contextos sociais existentes são importantes no entendimento do processo artesanal. Os conceitos de artesanato devem ser produzidos com base na realidade de um conhecimento acumulado criando assim estudos que não visem à homogeneização do termo, mas sim, a amplitude de seu universo. Lima (2002) destaca que o universo artesanal não é uma realidade homogênea: pressupõe modos de fazer diferentes, estilos de vida diferentes, visões de mundo diferentes e também estéticas diferentes.

As duas definições também enfatizam a questão do trabalho manual. Katinsky (1991) tem uma visão diferente e trata o artesanato moderno em oposição à indústria moderna, definindo o artesanato como um modo de produção. No artesanato o uso de máquinas está sempre subordinado ao operador, ou seja, o seu uso não busca economizar tempo ou mão de obra, como ocorre na indústria, mas sim, trazer comodidade ao artesão. Ele não questiona o quanto manual necessita ser o trabalho para ser artesanato, mas sim como ocorre sua relação com máquinas e instrumentos. Quem determina o ritmo de produção é o artesão, que impõe sua marca ao produto. Outra característica desse modo de produção diz respeito ao número de operadores, que tende a ser pequeno, e todos eles dominam integralmente as atividades necessárias para a produção do objeto. Fato que contrasta com as manufaturas, que tendem a ser especializadas e com grande divisão de trabalho, logo seus funcionários não conhecem o processo como um todo. Por fim, o autor aponta a questão de investimentos. Enquanto o foco da indústria moderna é o capital intensivo, no artesanato o foco é a mão de obra intensiva.

Ainda, em relação à manualidade do trabalho artesanal, o antropólogo Ricardo Lima $^{5} \mathrm{faz}$ um interessante debate. O autor questiona a oposição que se faz entre arte e artesanato, separando os agentes sociais que dão concretude aos objetos através do trabalho manual. Ele considera essa separação uma distinção de classes sociais, o que faz uma oposição entre o saber e pensar das elites e o mero fazer das camadas populares. O pesquisador cita Arantes, que diz que a "dissociação entre 'fazer' e 'saber', embora a rigor falsa, é básica para a manutenção das classes sociais, pois ela justifica que uns tenham poder sobre o labor dos outros." Esse quadro condena a produção popular ao domínio da irracionalidade, da inconsciência e da espontaneidade do fazer. No entanto, uma das características da produção artesanal é justamente a integração da atividade manual com a intelectual. Apresentando-se como o oposto da produção industrial, em que devido ao princípio da divisão social do trabalho e da especialização essas instâncias podem se apresentar separadas. E ainda sobre esse discurso elitista, o autor se refere à Sylvia Porto Alegre:

“Toda discussão sobre fronteiras entre 'arte' e 'artesanato', entre 'artista' e 'artesão', a partir do discurso dominante, carece de sentido dentro da perspectiva do indivíduo que exerce essa atividade pois ele raramente separa a instância do trabalho manual ou mecânico ('artesanal') do trabalho intelectual e confere a ambos igual dignidade." (Porto Alegre apud Lima, 1998)

\footnotetext{
${ }^{5}$ Informações extraídas do texto preparado, em primeira versão sob o título "Engenho e arte", para o Programa Um Salto para o Futuro, da TVE do Rio de Janeiro. Disponível em: http://www.cnfcp.gov.br/pdf/Artesanato/Artesanato_e_Arte_Pop/CNFCP_Artesanato_Arte_Popular_Gomes_Lima.pd $f$
} 
Lima propõe um redirecionamento do uso das palavras artesanato e arte, já que os termos são aplicados a diferentes planos discursivos de uma mesma realidade. Assim, o artesanato deveria se referir ao processo de produção de um objeto e suas técnicas produtivas, não importando se confeccionados por mãos eruditas ou populares. Entretanto, ao falar do mesmo objeto, mas observando as questões de estética, de equilíbrio, de proporções, de contrastes, de ritmo, de cores, ou ainda, seus conteúdos simbólicos e sistemas de significados, estamos falando de arte - não importando se o objeto for de origem erudita ou popular.

Para Foucault todo discurso é uma forma de poder:

\begin{abstract}
Quero dizer que em uma sociedade como a nossa, mas no fundo em qualquer sociedade, existem relações de poder múltiplas que atravessam, caracterizam e constituem o corpo social e que estas relações de poder não podem se dissociar, se estabelecer nem funcionar sem uma produção, uma acumulação, uma circulação e um funcionamento do discurso. (Foucault, 1979)
\end{abstract}

Esse discurso dominante da elite em relação ao artesanato, apresentado por Lima, é uma forma de poder como destaca Foucault. Ele mostra uma tendência de dominação da elite que ao desvalorizar o artesanato, desvaloriza seus produtores que geralmente estão nas classes C, D e E. Assim, enquanto os objetos artísticos são expostos em galerias refinadas e tem alto custo, os objetos artesanais são vendidos em feiras e possuem um baixo valor agregado.

Acredito que é importante fugir desses discursos dominantes e entender o artesanato como um fenômeno heterogêneo, complexo e diversificado que abrange dimensões socioculturais e econômicas presentes na sociedade contemporânea. É uma forma de expressão cultural, mas não está somente fincado na tradição e no passado, estando fadado ao desaparecimento. É uma atividade contemporânea que sofre alterações de acordo com os valores dos grupos sociais, o que tem garantido sua sobrevivência. Sendo assim, o produto artesanal é um objeto singular dotado de valor mercantil e simbólico, que tem um importante papel na promoção da inclusão social por meio da geração de renda e também no resgate de valores culturais e regionais. $O$ trabalho artesanal está imerso em redes de relações sociais ao longo da sua cadeia produtiva, que envolve as atividades de concepção, de produção, de comercialização e de consumo. As relações sociais entre os atores ao longo da cadeia podem ser concebidas como envolvendo relações de poder e de valor (KELLER, 2014).

\title{
2.2 Projeto: uma relação de poder
}

Nas relações de trabalho já estabelecidas dentro do artesanato foi incluída a atuação do designer. Essa ação é incentivada pelas políticas de fomento ao artesanato, principalmente a partir dos anos 1990, e buscam sua revitalização e sua adequação ao mercado.

Borges (2011) mostra vários exemplos de interferências negativas entre as duas áreas e afirma que, em geral, isso ocorre quando os designers se acham superiores aos artesãos, pelo simples fato de serem instruídos - essa postura é baseada nos discursos de elite vistos anteriormente. Em alguns casos, os designers visitando as comunidades geram ícones, alteram objetos e adicionam materiais que não pertencem ao contexto, reproduzindo imagens caricatas e simplórias. Há outra situação de imposição cultural, que é a ignorância ou o desinteresse a respeito da situação local. A partir dessa interferência mal concebida, os designers produzem um material raso de uma relação que é profunda, e o apresenta em exposições e livros sofisticados, sendo reconhecidos por seu "trabalho social". O artesão, no entanto, não utiliza esse material, ele não se reconhece nessa produção imposta. A relação custo-benefício desse tipo de encontro é 
muito desfavorável. Para um encontro mais saudável é preciso respeitar o trabalho artesanal e os signos que resistem há tempos em sua produção.

Ao artesão não cabe somente à função do fazer. Ele participa de toda a cadeia de produção desde as atividades de projeto do produto, passando pela confecção, pela comercialização e pelo marketing até o seu consumo final. A função do designer não pode ser a de conceber produtos no lugar dos artesãos. Quando isso acontece voltamos para a lógica de dominação que enxerga o artesanato apenas como um fazer manual, enquanto a atividade intelectual pertence ao designer.

Argan (1993) define projeto como uma imagem, que é feita visando uma execução técnica. Projeto é, ainda, uma relação direta entre uma atividade intelectual e uma atividade manual e é quase sempre uma atividade coletiva. O autor comenta que a atividade de projeto não se manifesta somente nas artes, mas em todas as atividades humanas, em toda cultura. Talvez pelo o artesanato possuir características das atividades pré-industriais - nas quais não havia a dissociação entre saber e do fazer e do trabalho intelectual e manual - exista ainda a ideia distorcida de que artesanato é somente o saber manual.

Considerando a ideia de projeto de Argan, podemos concluir que antes de qualquer atuação de design, os objetos artesanais já eram projetados para atender às necessidades dos próprios artesãos. Os objetos são imaginados e produzidos pelos artesãos a partir de elementos da cultura. Borges (2011) diz que os artefatos artesanais são projetados (por artesãos ou designers) para atender determinada função de uso, a partir do emprego de determinadas matérias-primas e determinadas técnicas produtivas.

O designer tem o papel de facilitador atuando, por exemplo, na redefinição das características tangíveis do artefato, na racionalização da produção e na ampliação dos canais de venda do produto (FILHO, 2009). Isso porque possui conhecimento técnico sobre materiais e técnicas produtivas, entende de questões mercadológicas, possui ferramentas para criação de identidade e marcas - o que auxilia no processo de identificação e explicitação da identidade local e na criação de marcas para os produtos artesanais, que tornem tangíveis sua identidade e facilite sua inserção no mercado. Nesse processo de interferência, o artesão deve ser visto como protagonistas e não coadjuvantes, isto é, mão de obra sem autonomia criativa, o que acarretaria à proletarização do artesão.

Talvez possamos considerar o artesanato como um saber dominado. Foucault (1979), no texto Genealogia e poder, explica que o saber dominado se refere a uma série de saberes desqualificados, ou insuficientemente elaborados: saberes ingênuos, hierarquicamente inferiores, saberes abaixo do nível requerido de conhecimento ou de cientificidade. $O$ autor o classifica como saber das pessoas, que não é de forma alguma um saber comum, um bom senso, mas, ao contrário, um saber particular, regional, local, um saber diferencial incapaz de unanimidade e que só deve sua força à dimensão que o opõe a todos aqueles que o circundam. Esse saber, assim como o artesanato, é desqualificado pela hierarquia dos conhecimentos e das ciências, e existe uma luta de poder entre os dois discursos. Por fim, ele questiona que ao se colocar em circulação estes elementos do saber dominado, não correm eles o risco de serem recodificados, recolonizados pelo discurso unitário, que depois de tê-los desqualificado e ignorado quando apareceram, está agora prontos a anexá-los ao seu próprio discurso e a seus efeitos de saber e de poder? Uma questão que surge é que o designer e as instituições de fomento, ao interferirem no artesanato, não estariam buscando sua recolonização?

Del Gaudio (2014) com base nos pensamentos de Foucault explica que o poder é um elemento que define as relações entre parceiros, ao mesmo tempo em que pode ser definido por elas, mas não se reduz a essas relações, é também produzido por meio de ações que provocam alterações em outras ações. A autora relaciona esses conceitos aos atores em uma rede de projeto - no caso desse trabalho, podemos considerar a rede formada entre designers, artesãos e influenciada pelos agentes de fomento -, na qual a expressão das dinâmicas de poder existente 
entre eles exerce influência na implementação das ações. O contexto em que é desenvolvida a interferência do design no artesanato pode ser considerado como um espaço de síntese das forças (de poder) exercidas pelos atores nele existentes. O desenvolvimento dessas relações é influenciado, portanto, pelo exercício das forças existentes no contexto. Em uma interferência entre as áreas deve existir, então, a partilha e a perda de poder do designer e do artesão, que são determinados pela configuração da rede de projeto.

Muitas vezes o designer não quer dividir o poder e projetar juntamente com o artesão e acaba impondo um projeto sem futuro. Uma situação curiosa, porque o designer, ao menos, deveria ser capacitado para trabalhar em equipes multidisciplinares. Forty (2007) destaca que essa é uma atividade por natureza, social e não puramente individual. Entretanto, se disseminou um mito da autonomia criativa, da onipotência sobre todo seu processo de produção e falsa ideia de um gênio criativo. Isso gera nos designers ilusões grandiosas sobre a natureza de seu trabalho, tornando alguns profissionais prepotentes, que não estão preparados para compartilhar o poder.

$\mathrm{O}$ artesão também pode não querer partilhar o poder que detém sobre sua criação, já que possui autonomia sobre seu processo produtivo. Aceitar um profissional de fora do contexto, tido como intelectual, que vai interferir em sua produção pode causar conflitos, principalmente, se a interferência busca deslocar sua função passando a ser mão de obra na execução de um projeto cuja autoria é do designer.

Nessas relações de poder, o agente de fomento também deve ser considerado, já que a maioria das ações se dá através dele. Eles dão diretrizes para como o designer e artesãos devem agir. No caso do artesão, por exemplo, esperam que ele seja empreendedor e os organiza em associações. Essas associações visam fortalecer o artesão frente aos comerciantes conhecidos como 'atravessadores', mas podem gerar muitos conflitos internos, assim como a necessidade do empreendedorismo.

Keller (2014) afirma que as ações de intervenção de agências e de políticas governamentais visam preservar e valorizar o artesanato, mas, falham nos seguintes aspectos: em reconhecer e promover as necessidades dos trabalhadores do artesanato; em reconhecer os saberes locais; e ao reproduzirem as políticas top-down. É importante ouvir o artesão e entender suas reais necessidades. Nesse sentido, Deleuze em debate com Foucault, no livro a Microfísica do poder (1979), argumenta que quando as pessoas começam a falar e a agir em nome delas mesmas não opõem uma representação, mesmo invertida, a uma outra, não opõem uma outra representatividade à falsa representatividade do poder.

\subsection{Estética e mercado}

Vários autores questionam as interferências que causam perda dos referenciais culturais, em detrimento das necessidades comerciais, tornando o produto artesanal sem identidade o que acaba gerando perda de mercado. A busca pela valorização mercantil do artesanato deve ocorrer em conformidade com a preservação das características simbólicas inerentes a prática que lhe dá origem como aponta Filho (2009). A incorporação do artesanato na vida moderna ocorre em função de seu significado, já que diferentemente dos objetos industriais/funcionais, que só existem no presente e esgotam-se com seu uso, os objetos artesanais falam-nos da passagem do tempo e da origem. (CARNIATTO et al. 2008).

Em relação a essa questão, Lima (2002) argumenta que a produção artesanal não deve ser pautada em questões de gosto que supostamente atendam ao mercado. Ele questiona a qual mercado se quer atender, já que existe uma variedade regional e cultural e também distinções de classes sociais, estilos de vida e visões de mundo, o que acarreta em percepções estéticas diferentes. O autor questiona se o direcionamento estético do artesanato para atingir determinado mercado não acaba restringindo sua venda a apenas essa comunidade. Outro ponto 
é que ao se falar de gosto está se falando de subjetividades e é muito complicado atendê-las. É possível definir determinados ferramentas que orientam as escolhas, mas, no fundo, ao particularizar as preferências, o gosto, se resvala para o terreno da subjetividade. $O$ gosto, na sociedade em que vivemos, também está associado a padrões de fruição e consumo ditados por moda e fortemente influenciado por tendências criadas artificialmente, enquanto o artesanato está baseado em referências culturais que não mudam da noite para o dia. Lima acredita que em intervenções desse tipo se perde o valor agregado do produto artesanal, ou seja, sua identidade cultural, que fornece sua procedência. Vira mera mercadoria, igual a qualquer mercadoria da indústria, ficando totalmente descaracterizado e culturalmente empobrecido.

Lima (2002) defende que as intervenções, portanto, não devem se centrar na forma dos objetos - que são consagradas ao longo de anos e atestada pelo uso de gerações e gerações -, mas sim em melhoramentos de sua funcionalidade, quando essas estão mal resolvidas. $E$, geralmente quando isto acontece, é em decorrência de problemas que estão no plano das relações sociais da produção, que devem ser identificados, para melhor equacioná-los e buscar solução.

O designer não possui primazia do gosto e quando atua em comunidades artesãs não pode usar esse critério para ação. Ele não pode hierarquizar de maneira nenhuma o olhar sobre uma produção a partir do seu gosto subjetivo. É preciso respeitar as características simbólicas presentes nessa realidade. Já a interferência no campo funcional, acontece em outro nível, visto que ninguém quer, por exemplo, adquirir um produto que se quebre ao primeiro toque, ou, um pote de água que não consiga reter a água (LIMA, 2002). É importante destacar que mesmo essa interferência não pode ser uma imposição, ela tem que partir de necessidades da comunidade.

Uma estratégia em relação ao mercado é a de educação, adequando o público ao objeto e não o contrário. Podem-se informar os valores intangíveis desse objeto, sua importância cultural e suas características simbólicas. O designer tem muito a auxiliar nesse processo criando uma identidade visual, que reflita e transmita esses valores. O material promocional, por exemplo, pode mostrar por quem foi feito o artefato e contar um pouco da história do objeto e de seu artesão.

\section{CONCLUSÃO}

Não quero dizer com esse trabalho que todas as relações entre design e artesanato são mal conduzidas, negligenciando o fator cultural e gerando resultados negativos. Borges (2011) comenta que em projetos já realizados sobre a interferência do design no artesanato algumas consequências positivas foram observadas: o desenvolvimento econômico local, a transformação social, o reforço da identidade cultural nos produtos e a preservação da cultural e ambiental local. O que este trabalho procurou fazer foi entender os discursos de poder envolvidos nessas ações, para que não se caia em prática reducionista. A interferência não deve ser só do design no artesanato, mas sim uma via de mão dupla, pois o designer tem muito a aprender com os artesãos.

Como é relativamente recente essa aproximação dos dois campos, ainda é necessária uma análise mais profunda sobre essas relações para que o designer possa atuar nessas comunidades de forma mais responsável e coerente. Sem que aja uma imposição de saberes. O que temos é uma relação e os dois campos se beneficiam dessa troca.

Estudar as relações entre design e artesanato em última análise é uma forma de refletir sobre o papel do designer em nossa sociedade.

\section{REFERÊNCIAS}


ABBONIZIO, MARCO A. DE O. Aproximação teórica das intervenções de design no artesanato com os princípios pedagógicos de Paulo Freire: Caminhos para uma prática emancipatória. 2009. 137f. Dissertação (Mestrado em Design) - Universidade Federal do Paraná, Curitiba. 2009. ANDRADE, Erica Ribeiro de. Interferências do design na dimensão econômica da sustentabilidade. 2012. 209f. Dissertação (Mestrado em Design) - Universidade Federal de Santa Catarina, Florianópolis. 2012.

ANASTASSAKIS, Zoy. Aloísio Magalhães e o Centro Nacional de Referência Cultural, ou como fazer pesquisa em design sem sabê-lo. In: Congresso Internacional de Pesquisa em Design, 2007, Rio de Janeiro. Anais do 4 Congresso Internacional de Pesquisa em Design, 2007.

ARGAN, G. C. A História na Metodologia do Projeto. Revista Caramelo, São Paulo, no 6, p; 156-170, 1993.

BORGES, Adélia. Design + Artesanato: o caminho brasileiro. São Paulo: Terceiro Nome, 2011. CARNIATTO, I. V.; KISTMANN, V. B.; A.TEIXEIRA J. In: Congresso Brasileiro de Cerâmica, 2008, Florianópolis. Anais do 52 Congresso Brasileiro de Cerâmica, 2008.

DEL GAUDIO, Chiara. Design Participativo e inovação social: a influência dos fatores contextuais. 2014. 153f. Tese (doutorado) - Pontifícia Universidade Católica do Rio de Janeiro, Departamento de Artes e Design, Rio de Janeiro. 2014.

FILHO, Clovis dos Santos Dias. Produção, distribuição e consumo dos bens simbólicos: uma reflexão sobre os programas de apoio ao artesanato. In: Encontro de Estudos Multidisciplinares em Cultura, 2009, Bahia. Anais do 5 Encontro de Estudos Multidisciplinares em Cultura, 2009. FOUCAULT, Michael. Microfísica do poder. Rio de Janeiro: Edições Graal, 1979.

FORTY, Adrian. Objetos de desejo - design e sociedade desde 1750. São Paulo: Cosac Naify, 2013. HAGE, Fernando. Múltiplos Artesanatos. IARA-Revista de Moda, Cultura e Arte, São Paulo, v.2 n. 1, set. /dez. 2009.

KATINSKY, Júlio Roberto. Artesanato moderno. In: Revista Artéria, Santos, v.2, n.3, p.45-50, agosto de 1991.

KELLER, Paulo F. O artesão e a economia do artesanato na sociedade contemporânea. In: Revista de Ciências Sociais, n. 41, pp. 323-347, outubro de 2014.

LIMA, Ricardo Gomes. Artesanato e arte popular: duas faces de uma mesma moeda? Disponível em:

<http://www.cnfcp.gov.br/pdf/Artesanato/Artesanato_e_Arte_Pop/CNFCP_Artesanato_Arte_Pop ular_Gomes_Lima.pdf> Acesso em: 04/06/2015. 
. Estética e gosto não são critérios para o artesanato. In: Central ArteSol. (Org.).

Artesanato, produção e mercado: uma via de mão dupla. São Paulo: Programa Artesanato Solidário, 2002. p. 23-37.

MANZINI, Ezio. Design para a inovação social e sustentabilidade: comunidades criativas, organizações colaborativas e novas redes projetuais. Rio de Janeiro: E-papers, 2008.

SERAFIM, Elisa Feltran. Design e artesanato: análise de modelos de atuação de design junto a grupos de produção artesanal. 2015. 150f. Dissertação (Mestrado em Design) - Universidade Federal de Pernambuco. Centro de Artes e Comunicação, Recife. 2015. 